\title{
Domoic Acid, Okadaic Acid and Spirolides: Inter-Species Variability in Contamination and Cooking Effects
}

\author{
C. Picot $^{1}$, G. Limon ${ }^{2}$, G. Durand ${ }^{2}$, N. Wesolek ${ }^{1}$, D. Parent-Massin ${ }^{1}$, A. C. Roudot $^{1, *}$ \\ ${ }^{1}$ Laboratoire de Toxicologie Alimentaire et Cellulaire, Université Européenne de Bretagne - Université de Bretagne Occidentale \\ (UEB-UBO), 6 Av. Victor Le Gorgeu - CS93837, 29238 Brest Cedex 3, France \\ ${ }^{2}$ IDHESA - Technopôle de Brest-Iroise, BP 52 - 120 Avenue de Rochon, Plouzané, 29280, France
}

\begin{abstract}
The inter-species variability of contamination by domoic acid (DA), okadaic acid and analogues (OAs) and spirolides (SPX) in mussels, oysters, cockles, carpet shell clams and razor clams was assessed. DA concentrations were measured using both high performance liquid chromatography (HPLC) with Ultra Violet (UV) detection and HPLC coupled with tandem mass spectrometry (HPLC-MS/MS); OAs and SPX were measured using HPLC-MS/MS. Observations showed that for each phycotoxin, the contamination rates are species-dependent and the most contaminated species differ according to the kind of phycotoxin. For DA and SPX, cockles appear to be the most contaminated species whereas mussels seem to be the predominant vector for OAs. The effect of cooking process on DA concentrations was investigated in five different bivalve species by comparing toxin concentrations in whole raw flesh with concentrations in whole cooked flesh. The DA concentration decreased in cooked cockles and razor clams whereas it increased in cooked mussels, carpet shell clams and donax. Thus the impact of cooking is bivalve species-dependent. For OAs and SPX, the cooking process was studied on mussels and resulted in an increase in the toxin concentration because of their lipophilic nature. These results should be taken into consideration in exposure assessments and in the design of regulatory monitoring programs, as the current banning levels based on raw bivalves may over- or under-protect consumers when shellfish are eaten cooked.
\end{abstract}

Keywords Inter-species variability, shellfish, cooking effect, phycotoxins

\section{Introduction}

Phycotoxins are secondary metabolites produced by toxic phytoplankton which can be accumulated in the food chain (particularly in bivalves) and thus can cause food poisoning when bivalves are ingested by human beings[1-2]. Among known phycotoxins, we will focus on three groups of toxins which are the main sources of contamination in Western Brittany (France): domoic acid (DA) and analogues; okadaic acid (OA) and analogues (dinophysistoxins, DTXs); and spirolides (SPXs). DA and some of its isomers (e.g. epi-DA) are known to be Amnesic Shellfish Poisoning (ASP) toxins. In humans, DA can cause gastroenteritis and produce neurodegeneration and central nervous system dysfunction, notably loss of short-term memory[3]. Historically, OA and its congeners (OAs) are classed under Diarrheic Shellfish Poisoning (DSP) because of the symptoms they cause (gastrointestinal distress, diarrhoea, nausea, vomiting and abdominal pain)[4]. SPXs are toxins identified more recently, and so far no case of human illness due to SPXs has been reported. They are however classified as

* Corresponding author:

alain-claude.roudot@univ-brest.fr (A.C. Roudot)

Published online at http://journal.sapub.org/fph

Copyright (C) 2012 Scientific \& Academic Publishing. All Rights Reserved fast-acting toxins due to symptoms caused in mice[5].

Over the past few decades, phycotoxins have become increasingly controlled and considered as an important food safety issue because of their expansion. They can have a significant impact on humans, however accurate data on exposure to phycotoxins via shellfish consumption are very limited. On this point, the European Food Safety Authority (EFSA) scientific panel noted i) the lack of representative data on the contamination of shellfish notably regarding the species of shellfish and ii) the lack of data on the possible impact of shellfish processing (e.g. cooking). The aim of this work is to obtain these data, as recommended by the panel.

Phycotoxin levels are heavily dependent on the shellfish species. Each phycotoxin seems to have dominant contamination vectors, depending on the bivalve's ability to accumulate and to depurate (more or less quickly) phycotoxins. For instance, Hess et al. (2001) ([6]) showed, in Scotland, that for domoic acid, $73 \%$ of scallops, $50 \%$ of razor clams and only $26 \%$ of mussels were affected. James et al. (2005) ([7]), in Ireland, obtained greater differences with $89 \%$ of scallops, and only $2 \%$ of mussels for the same toxin. In these two studies, the level of contamination was also the highest in scallops (up to $240 \mu \mathrm{g} / \mathrm{g}$ ) and the lowest in mussels $(0.09 \mu \mathrm{g} / \mathrm{g})$. For OAs, mussels are often considered as the sentinel species because they are the species the 
most often contaminated and with the highest concentrations[8-9]. However, specific studies concerning inter- species variability are limited or inexistent (for SPXs). The majority of studies do not involve species taken at the same time and location. Thus we chose to conduct a specific inter-species study on bivalves harvested at the same time and location. The bivalve species were the five of the most popular species in our area of interest: mussels (mytilus edulis), oysters (crassostrea gigas), cockles (cerastoderma edule), razor clams (ensis spp. or solen spp.) and carpet shell clams (ruditapes spp.).

In terms of consumer health protection, knowledge of the effects of processing on the phycotoxin levels is very important because bivalves can be consumed both raw and cooked. Previous studies have shown that cooking can have a significant effect on the concentration and distribution of various toxin groups in a variety of molluses. The loss of fluid during the cooking process generally determines the increase or decrease in toxin levels in shellfish depending on the hydrophilic or lipophilic nature of the toxin.

Concerning the effects of the cooking process on DA levels, several conclusions have been drawn: i) the reduction of visceral DA concentration and the diffusion of toxins through the tissues because of this hydrophilic nature [10]; ii) the minimal effect (nil or a slight increase by $20 \%$ ) of conventional steaming on the DA level of whole mussel tissue[11]; and iii) the difference in the effect of the cooking process according to the bivalve species[12]. Concerning lipophilic toxins, such as azaspiracids (AZAs) and OAs, an opposite influence of steaming has been reported, that is consistent with their lipophilic nature. Hess et al. (2005)[13] reported that processing of fresh raw mussels resulted in a two-fold increase in AZA levels in both whole flesh and digestive gland tissue compared to uncooked flesh. This change was attributed to water loss during steaming and was confirmed by McCarron et al. (2009)[14] who investigated the effect of heating on AZAs in the absence of water loss. In the same way, McCarron et al., (2008)[15] and Reboreda et al. (2010)[16] concluded that a steaming, autoclaving or boiling treatment increased the level of OA toxins (OA and DTX2) in the whole mussel flesh. Concerning processing effects on SPXs, no information is available. However, given their lipophilic nature, it is reasonable to assume that they would exhibit similar behaviour to AZAs and OAs. Depending on the toxin and the bivalve species, processing seems to have a different influence on shellfish toxicity (the toxin content of shellfish may fall below or rise above the regulatory limit). However literature on the influence of cooking on phycotoxins is sparse[17]. The aim of this study was to examine the effect of cooking on concentrations in different shellfish (mussels, cockles, donax, razor clams, carpet shell clams) for DA, OAs and SPXs.

This study was undertaken to examine the potential effect of different parameters on the phycotoxin levels in shellfish and their consequences on food safety. Firstly the difference in contamination according to the shellfish species (interspecies variability of contamination) was investigated. Then the influence of the cooking process was assessed. Lastly the difference in cooking process impacts between shellfish species was studied for DA.

\section{Material and Methods}

\subsection{Standards and Chemicals}

Water was deionized and passed through a Milli-Q water purification system (Millipore, Billerica, MA, USA). Acetonitrile (HPLC-MS grade) was purchased from Carlo Erba (Val de Reuil, France). Methanol (absolute, HPLC-MS grade), trifluoroacetic acid (TFA) and ammonium formate were purchased from Fisher (Loughborough, United Kingdom). Ammonium hydroxide (25\%), hydrochloric acid (37\%) and sodium hydroxide (32\%) were purchased from Merck (Darmstadt, Germany). Formic acid was purchased from J.T Baker (Deventer, the Netherlands). The certified reference materials (CRMs) DA (CRM-DA-f 100.7 $\pm 2.1 \mu \mathrm{g}$ $\mathrm{mL}^{-1}$ ), OA (CRM-OA-b $14.3 \pm 1.5 \mu \mathrm{g} \mathrm{mL}^{-1}$ ), 13-desmethyl spirolide-C (SPX1) (CRM-SPX1 7.0 $\pm 0.4 \mu \mathrm{g} \mathrm{mL}^{-1}$ ), MusC (CRM-ASP-Mus-c $\left.41 \mu \mathrm{g} \cdot \mathrm{g}^{-1} \mathrm{DA}\right)$ and MusB (CRM-DSPMus-b $10.1 \mu \mathrm{g} . \mathrm{g}^{-1} \mathrm{OA}$ ) were purchased from the National Research Council, Institute for Marine Biosciences (Halifax, Canada).

\subsection{Sample Preparation}

Naturally contaminated shellfish were harvested from the northwest coast of France (Auberlac'h and Cap Coz, Finistère). The samples were harvested monthly (when tide coefficient was > 95) from June 2009 to June 2010. Samples were carried in a cool box containing local sea water or in a basket with wrack to keep them cold, respectively for dug up bivalves and non dug up bivalves. Samples were taken to the laboratory, shells were removed and flesh was frozen within 12 hours of being removed from the water. In order to assess inter-species variability of contamination, shellfish were collected on the same day from the same location.

\subsection{Cooking Process of Shellfish Samples}

Live harvested shellfish were randomly separated into two batches. One sub-sample (containing at least $50.0 \mathrm{~g}$ of flesh) was left raw and a second was cooked as consumed by people (whole shellfish steamed for a short time in a pan over heat, for about 3-5 minutes). After removing the whole flesh of each sub-sample from the shell, homogenisation was carried out using a domestic blender. Mussels were homogenized both with and without cooking juice whereas all other species were homogenized without cooking juice. The samples were then split into two equal parts and frozen at $-80^{\circ} \mathrm{C}$ or $-20^{\circ} \mathrm{C}$ for analysis of lipophilic toxins or DA, respectively.

\subsection{Domoic Acid Analysis}

\subsubsection{Extraction}

A minimum of $50.0 \mathrm{~g}$ of tissues were removed and finely blended with a domestic blender. Accurately weighed $4.00 \mathrm{~g}$ 
subsamples were extracted in $50 \mathrm{ml}$ centrifuge tubes with 10 $\mathrm{ml}$ of $\mathrm{MeOH} / \mathrm{H}_{2} \mathrm{O}(50: 50, \mathrm{v} / \mathrm{v})$ for three minutes at 13,000 rpmi with a T25 Ultraturrax homogeniser (IKA ${ }^{\circledR}$ Works, Wilmington, NC, USA). Sample adhering to the Polytron probe was rinsed into a second tube using $6 \mathrm{ml}$ of extraction solvent and briefly homogenized. This rinse was saved for the second extraction. The first crude extract was centrifuged (Jouan, C412) at 4,800 rpmi for ten minutes. The supernatant was transferred to a $50 \mathrm{ml}$ volumetric flask. The probe rinse solution in the second tube was added to the tissue residues and vortex mixed. Following centrifugation the two supernatants were combined. Aliquots of the final extract were filtered through $0.20 \mu \mathrm{m}$ filters (PVDF/GF, Interchim) into HPLC vials[18]. These filtered extracts were analysed directly without further clean up.

\subsubsection{HPLC-UV-PDA analysis for DA}

DA was determined as the sum of DA and epi-DA, closely following the procedure published by Quilliam et al. (1995) [18], without the clean-up step and with some minor modifications. A Waters HPLC system coupled to a photodiode array detector (PDA) was used with a $\mathrm{C}-18$ column (QK Uptisphere, $250 \mathrm{~mm}, 4.6 \mathrm{~mm}, 5 \mu \mathrm{m})$ maintained at $40^{\circ} \mathrm{C}$. The elution system was as follows: phase A was water containing $0.11 \%$ TFA and phase B was acetonitrile, both delivered at 1 $\mathrm{mL} / \mathrm{min}$. Phase A decreased quickly from 92 to $91 \%$ from 0 to 10 minutes; decreased slowly from 91 to $90 \%$ from 10.01 to 20 minutes (to improve separation of DA from tryptophan to $>2.5$ minutes); decreased linearly to $0 \%$ from 20.01 to 32 minutes and held until 35 minutes at $0 \%$ and then increased to initial conditions during 10 minutes.

\subsubsection{HPLC-MS/MS Analysis for DA}

DA was also determined by High Performance Liquid Chromatography-tandem Mass Spectrometry (HPLCMS/MS). Chromatographic separation was achieved using a Waters Alliance 2690 HPLC system (Waters, Guyancourt, France). Separation was achieved on a Luna C18 $(150 \mathrm{~mm} \times$ $2 \mathrm{~mm}, 3 \mu \mathrm{m}$ ) column maintained at $40^{\circ} \mathrm{C}$. Mobile phase A was water and mobile phase B was acetonitrile/water (95:5, $\mathrm{v} / \mathrm{v}$ ), both containing $2 \mathrm{mM}$ ammonium formate and $50 \mathrm{mM}$ formic acid. The gradient started at $6 \%$ phase B. Phase B increased linearly to $85 \%$ in 10 minutes then to $90 \%$ in 11 minutes and to $100 \%$ in 4 minutes. A flow rate of $0.2 \mathrm{~mL} /$ min and an injection volume of $10 \mu \mathrm{L}$ were used. Massspectrometric detection was performed using a Micromass Quattro Ultima tandem mass spectrometer (Waters- Micromass, Manchester, UK) equipped with an electrospray ionization (ESI) interface. The mass spectrometer was operated in positive ESI mode. Cone voltage and collision energy were optimized. Two product ions were selected for each toxin to allow quantification as well as identification of the specific toxin.

\subsection{Lipophilic Toxin Analysis}

\subsubsection{Extraction}

The group of lipophilic toxins covered both OAs and SPX.
Two grams of whole-flesh tissue shellfish homogenate were extracted in duplicate. For the first extraction, homogenates were homogenized with $9 \mathrm{ml}$ methanol with a T25 Ultraturrax homogeniser at $11,000 \mathrm{rpm}\left(\right.$ IKA ${ }^{\circledR}$ Works, Wilmington, NC, USA) for two minutes. The extract was centrifuged for six minutes at 4,800 rpmi. The supernatant was transferred to a $20 \mathrm{ml}$ volumetric flask. Ultraturrax was washed with $9 \mathrm{ml}$ methanol and this methanol was used for the second extraction. In the second extraction, after centrifugation, washing methanol was added to tissue residues and vortex mixed for two minutes. The extract was centrifuged for six minutes at 4,800 rpmi. The supernatant was transferred to the first $20 \mathrm{ml}$ volumetric flask and the volume was made up to $20 \mathrm{ml}$ with methanol. The crude shellfish extract was filtered through a PTFE $0.45 \mu \mathrm{m}$ membrane filter (Phenomenex, Torrance, CA, USA) prior to being purified by SPE.

\subsubsection{Hydrolysis of Esters}

For determination of the ester forms of OA, DTX1 and DTX2 present in the shellfish sample, alkaline hydrolysis was performed. In a test tube, $500 \mu \mathrm{l}$ of $2.5 \mathrm{M}$ sodium hydroxide solution was added to $4 \mathrm{ml}$ of the centrifuged crude extract. The contents of the closed tube were mixed and the tube was placed in an oven at $76^{\circ} \mathrm{C}$. After 40 minutes the hydrolysed extract was cooled to room temperature and neutralized with $500 \mu \mathrm{l}$ of $2.5 \mathrm{M}$ hydrochloric acid. To check for evaporation of methanol during heating of the test tubes, they were weighed before and after hydrolysis. Extracts were purified by SPE before HPLC-MS/MS analysis. Toxins released by hydrolysis were calculated by subtracting free toxin levels measured in the unhydrolysed extract.

\subsubsection{SPE Procedure}

The SPE procedure was carried out as described by Gerssen et al. (2009). Strata-X cartridges, $60 \mathrm{mg}, 3 \mathrm{~mL}$ (Phenomenex, Torrance, CA, USA), were conditioned and equilibrated using $3 \mathrm{~mL}$ of methanol and methanol/water $(30: 70, v / v)$, respectively. The methanolic shellfish extracts $(3 \mathrm{~mL}$ ) were diluted with $7 \mathrm{~mL}$ water. After $3 \mathrm{~mL}$ of diluted extract had been loaded onto the cartridge, the cartridge was washed with $3 \mathrm{~mL}$ methanol/water $(10: 90, \mathrm{v} / \mathrm{v})$ containing $0.1 \% \mathrm{v} / \mathrm{v}$ of a $25 \%$ ammonium hydroxide solution in water. Finally, the toxins were eluted from the cartridge with $3 \mathrm{~mL}$ methanol.

\subsubsection{HPLC-MS/MS Analysis for Lipophilic Analysis}

Lipophilic toxins (OAs and SPX) were analyzed by HPLC-MS/MS following the procedure published by Gerssen et al. (2009)[19], with some modifications. It corresponds to the system and the conditions used for DA.

\section{Results and Discussion}

In our area of interest, three kinds of phycotoxins (DA, OAs and SPX) have been identified. This study was under- 
taken to examine the potential effect of different parameters on the phycotoxin levels in shellfish and their consequences on food safety. The investigated parameters were: i) the difference in contamination according to shellfish species (inter-species variability of contamination); ii) the influence of the cooking process; and iii) the differences in cooking process impacts according to shellfish species. The most harvested local bivalve species (i.e. mussels, oysters, cockles, carpet shell clams, razor clams and donax) were studied. For DA quantitation in shellfish, two chromatographic methods were used: HPLC-UV and HPLC-MS/MS; for OAs and SPX (grouped under the name "lipophilic toxins") HPLC-MS/MS was carried out. Moreover the cooking process can increase the diffusion of DA[10] and OA group toxins from the digestive glands to the tissues[15], thus analyses were performed on the whole flesh (digestive glands and tissues). Indeed, McCarron et al. (2008)[15] concluded that, from a food safety perspective, analysis of whole flesh may be more appropriate for regulatory monitoring practices, particularly if samples have been cooked.

\subsection{Shellfish Inter-Species Variability of Contamination}

To investigate the differences in contamination between bivalves, five of the most harvested bivalves in the area of interest were collected at the same time and location. Sampling over one year showed three months of contamination for DA (thus three independent experiments) and two main months of contamination for OAs (including one month during which contamination was observed in the two sampled areas (leading to three independent experiments)).

Concerning DA, Table 1 summarises the DA concentrations in whole shellfish obtained by HPLC-UV and HPLCMS/MS for cockles, carpet shell clams, razor clams, oysters and mussels. Results obtain by the two methods are in the same order of magnitude, with a greater sensitivity for the HPLC-MS/MS method. The results revealed inter-species variability. In the three independent experiments, cockles were the most affected species whereas the classification of other species varied. Although mussels were responsible for the only one fatal outbreak of ASP in Canada, they do not appear to be the dominant contamination vector. In the same way, a previous study reported that pacific razor clams (Siliqua patula) could accumulate DA at significant levels, however in our study, examined razor clams (Ensis spp. and Solen spp.) revealed DA levels inferior to cockles. Nevertheless, these results are consistent with those obtained by Vale and Sampayo (2001)[20] and Grigoriadou et al. (2005)[21] who reported that cockles accumulated more than razor clams and carpet shell clams (Ruditapes), which in turn accumulated more than oysters and mussels. The low DA accumulation in the oysters is consistent with the fact that oysters rarely exceed the regulatory limit. The limited DA intake could be explained by i) a combination of reduced clearance rate and rejection of Pseudo-nitzschia spp. cells in pseudofeces (in case of the presence of monospecific, toxic Pseudo-nitzschia spp. blooms) or ii) a preferential rejection of Pseudo-nitzschia spp. cells in pseudofeces (in the event of a multispecific bloom in which Pseudo-nitzschia spp. make a lesser contribution to the total food supply)[22].

Tables 2 and 3 summarise the OAs and SPX concentrations in whole flesh obtained by HPLC-MS/MS for cockles, carpet shell clams, razor clams, oysters and mussels. For the family of OA and analogues, our samples only showed OA in free form. Neither DTX1 nor DTX2 were detected; yet after hydrolysis high levels of DTX3 were detected.

Table 1. DA concentrations $(\mu \mathrm{g} / \mathrm{g}$ ) in raw whole tissue measured in five different bivalve species from Cap Coz (Western Brittany, France), harvested at the same time and location, obtained for two or three different experiments (depending on the bivalve species)

\begin{tabular}{ccccc}
\multicolumn{5}{c}{ HPLC-UV determination of DA (ug/g total tissues) } \\
\hline Species & 30th March & 27th April & 14th May & Mean \\
\hline Cockle & 2010 & 2010 & 2010 & 2.11 \\
Carpet shell clam & 2.68 & 2.81 & 0.83 & 1.39 \\
Razor clam & 1.13 & 2.23 & 0.79 & 1.33 \\
Oyster & $\mathrm{nh}$ & 2.11 & 0.55 & 1.00 \\
Mussel & 1.37 & 1.32 & 0.32 & 0.80 \\
\hline
\end{tabular}

nh: non harvested (adverse weather conditions)

HPLC-MS/MS determination of DA ( $\mu \mathrm{g} / \mathrm{g}$ total tissues)

\begin{tabular}{ccccc}
\hline Species & 30th March & 27th April & \multicolumn{2}{c}{ 14th May } \\
& 2010 & 2010 & 2010 & 0.84 \\
Cockle & 2.73 & 3.71 & 0.59 & 2.43 \\
Carpet shell clam & 1.35 & 2.58 & 0.45 & 1.51 \\
Razor clam & nh & 2.52 & 1.49 & 0.45 \\
Oyster & 1.25 & 1.04 & 0.72 \\
Mussel & 1.18 & & 0.98 \\
\hline
\end{tabular}

nh: non harvested (adverse weather conditions) 
Table 2. OA concentrations (ng/g) in raw whole tissue measured in five different bivalve species from Cap Coz and Auberlac'h (Western Brittany, France), harvested at the same time and location for each experiment, obtained for two or three different experiments

\begin{tabular}{|c|c|c|c|c|}
\hline Species & $\begin{array}{c}\text { 30th March } \\
2010^{\mathrm{a}}\end{array}$ & $\begin{array}{c}27 \text { th April } \\
2010^{\mathrm{a}}\end{array}$ & $\begin{array}{c}\text { 14th May } \\
2010^{\mathrm{b}}\end{array}$ & Mean \\
\hline Cockle & 2264.4 & 1148.6 & 6.5 & 1139.8 \\
\hline Carpet shell clam & 949.5 & 956.0 & 30.6 & 645.4 \\
\hline Razor clam & 832.1 & 1378.6 & 7.0 & 739.2 \\
\hline Oyster & 275.0 & 204.7 & 14.4 & 164.7 \\
\hline Mussel & 1053.5 & 1586.6 & 124.8 & 921.6 \\
\hline
\end{tabular}

${ }^{\mathrm{a}} \mathrm{Cap} \mathrm{Coz}{ }^{\text {b: }}$ Auberlac'h

Table 3. SPX concentrations (ng/g) in raw whole tissue measured in five different bivalve species from Cap Coz and Auberlac'h (Western Brittany, France), harvested at the same time and location for each experiment, obtained for three different experiments

\begin{tabular}{ccccc}
\multicolumn{5}{c}{ HPLC-MS/MS determination of SPX (ng/g total tissues) } \\
\hline Species & $\begin{array}{c}14 \text { th May } \\
2010^{\mathrm{a}}\end{array}$ & $\begin{array}{c}\text { 29th May } \\
2010^{\mathrm{a}}\end{array}$ & $2010^{\mathrm{b}}$ & 11.3 \\
Cockle & 10.9 & 21.3 & 3.8 & 14.5 \\
Carpet shell clam & 6.0 & 7.6 & 4.7 & 5.8 \\
Razor clam & 4.3 & 7.8 & 4.7 & 5.6 \\
Oyster & 8.0 & 11.3 & 3.0 & 5.0 \\
Mussel & 4.6 & 9.3 & 5.7 \\
\hline
\end{tabular}

${ }^{\mathrm{a}}$ : Cap Coz; ${ }^{\mathrm{b}}$ : Auberlac'h

Table 4. DA concentration ( $\mu \mathrm{g} / \mathrm{g}$ of whole flesh) for both raw and cooked bivalve species; percentages of variation between raw and cooked concentrations and (raw toxin concentration / cooked toxin concentration) ratio values. A ratio greater than one means a decrease in DA concentration in whole flesh due to the cooking process whereas a ratio of less than one means an increase

\begin{tabular}{|c|c|c|c|c|c|c|c|c|}
\hline & \multicolumn{4}{|c|}{ Experiment 1} & \multicolumn{4}{|c|}{ Experiment 2} \\
\hline & $\begin{array}{l}\text { Raw } \\
(\mu \mathrm{g} / \mathrm{g} \\
\text { flesh })\end{array}$ & $\begin{array}{l}\text { Cooked }(\mu \mathrm{g} / \mathrm{g} \\
\text { flesh) }\end{array}$ & $\begin{array}{c}\% \text { of } \\
\text { variation }\end{array}$ & $\begin{array}{c}\text { Ratio } \\
\text { (Raw / Cooked) }\end{array}$ & $\begin{array}{l}\text { Raw } \\
(\mu \mathrm{g} / \mathrm{g} \\
\text { flesh) }\end{array}$ & $\begin{array}{l}\text { Cooked }(\mu \mathrm{g} / \mathrm{g} \\
\text { flesh) }\end{array}$ & $\begin{array}{c}\% \text { of } \\
\text { variation }\end{array}$ & $\begin{array}{c}\text { Ratio } \\
\text { (Raw / Cooked) }\end{array}$ \\
\hline Mussel * & 84.95 & 81.02 & -4.63 & 1.05 & 0.83 & 0.86 & 3.51 & 0.97 \\
\hline Mussel & 1.29 & 1.87 & 44.76 & 0.69 & 0.69 & 1.02 & 47.84 & 0.68 \\
\hline Cockle & 2.55 & 1.76 & -30.90 & 1.45 & 2.53 & 1.43 & -43.40 & 1.77 \\
\hline $\begin{array}{l}\text { Carpet shell } \\
\text { clam }\end{array}$ & 0.94 & 2.27 & 140.40 & 0.42 & 1.89 & 3.69 & 95.00 & 0.51 \\
\hline Razor clam & 2.01 & 1.57 & -21.89 & 1.28 & 0.28 & 0.26 & -5.41 & 1.06 \\
\hline Donax & 26.86 & 32.31 & 20.28 & 0.83 & 1.10 & 1.24 & 12.90 & 0.89 \\
\hline
\end{tabular}

*: with cooking juice; other bivalve species without cooking juice; nd: not determined

\begin{tabular}{|c|c|c|c|c|c|c|}
\hline & \multicolumn{4}{|c|}{ Experiment 3} & \multicolumn{2}{|c|}{ Mean } \\
\hline & $\begin{array}{c}\text { Raw } \\
(\mu \mathrm{g} / \mathrm{g} \text { flesh })\end{array}$ & $\begin{array}{c}\text { Cooked } \\
(\mu \mathrm{g} / \mathrm{g} \text { flesh })\end{array}$ & $\%$ of variation & $\begin{array}{c}\text { Ratio } \\
\text { (Raw / Cooked) }\end{array}$ & $\%$ of variation & $\begin{array}{c}\text { Ratio } \\
\text { (Raw / Cooked) }\end{array}$ \\
\hline Mussel * & 0.51 & 0.49 & -5.76 & 1.06 & -2.30 & 1.03 \\
\hline Mussel & nd & nd & nd & nd & 46.30 & 0.68 \\
\hline Cockle & 0.74 & 0.60 & -19.28 & 1.24 & -31.19 & 1.48 \\
\hline Carpet shell clam & 0.59 & 0.93 & 58.41 & 0.63 & 97.94 & 0.52 \\
\hline Razor clam & nd & nd & nd & nd & -13.65 & 1.17 \\
\hline Donax & nd & nd & nd & nd & 16.59 & 0.86 \\
\hline
\end{tabular}

Concerning OAs inter-species variability of contamination, as expected, mussels were the predominant vector for OAs in two out of three experiments. It should be noted however that concentrations in cockles, razor clams and carpet shell clams also reached significant levels. This result must be taken into account in monitoring programs: mussels are not the only species which can exceed the regulatory limit and in one experiment, cockles also surpass mussel concentration. On the contrary, the least contaminated species seems to be oysters. Concerning SPX, in the three independent experiments, cockles and oysters were the first and second most contaminated species, respectively.
To the best of our knowledge, no studies on inter-species variability of SPX contamination have been performed before. This study can therefore give an initial indication of the choice of the species of interest for future studies and for prioritization in food safety.

To conclude, phycotoxin contamination rates are species-dependent and the dominant contamination vector is phycotoxin-dependent. For DA and SPX, cockles appear to be the most contaminated species whereas mussels seem to be the predominant vector for OAs. These contamination differences must be taken into account in case of phycotoxin exposure assessment and in the choice of monitored 
species in national monitoring programs.

\subsection{Cooking Process of Shellfish Samples}

Mussels were analysed both with and without cooking juice whereas all other species were analysed without cooking juice.

\subsubsection{Cooking Process Impact on DA Concentrations}

DA concentration was affected by the cooking process in very different ways in the five species studied. The cooking process led to a decrease in DA concentration in cockles $(31 \%)$ and in razor clams $(14 \%)$. On the contrary, DA concentrations were higher than uncooked samples in cooked mussels (46\%), carpet shell clams $(97 \%)$ and donax $(17 \%)$ (Figure 1, Table 4). The difference between cockles and carpet shell clams, in terms of response to cooking, is totally consistent with results obtained by Vidal et al. (2009) who also observed that cockles lost a significant part of their DA content, while Manila clams did not. The results concerning the impact of cooking on mussels were consistent with those obtained by McCarron et al. (2006)[23] who found that DA concentrations in mussels were unaffected or actually underwent a slight increase $(20 \%)$ depending on the harvest location.

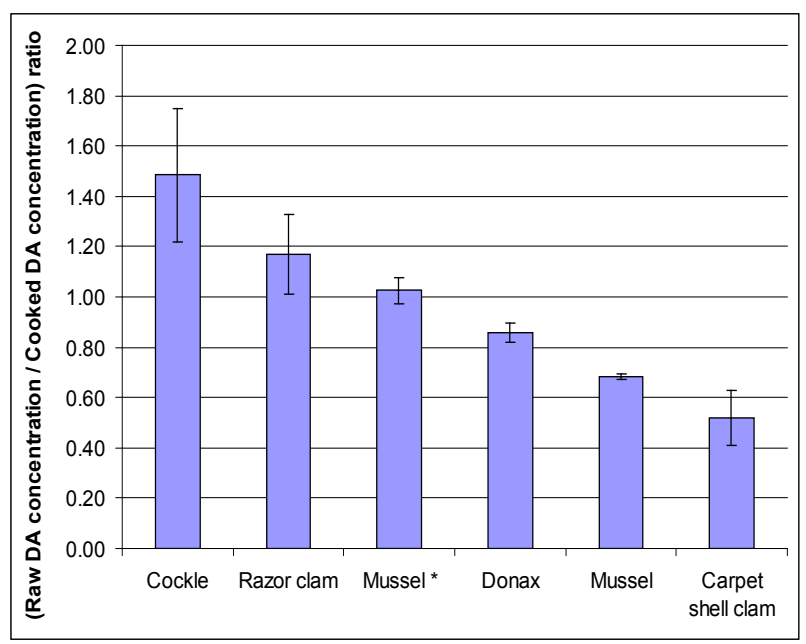

Figure 1. Comparison of mean (raw DA concentration / cooked DA concentration) ratio values between the five different bivalve species. A ratio greater than one means a decrease in DA concentration in whole flesh due to the cooking process whereas a ratio of less than one means an increase. Means are obtained from two or three different experiments (depending on bivalve species). Error bars represent \pm 1 SD. * Mussels with cooking juice

To explain these results, we recall that the cooking process of bivalves containing DA affects two parameters which have opposite effects on DA concentrations in cooked meat: i) weight loss as a result of evaporation of flesh fluids; ii) DA loss as the fluids leave the matrix because of the hydrophilic nature of DA. Thus, the increase or decrease in DA concentration in cooked bivalves depends on the balance between the increase caused by weight reduction and the decrease derived from DA loss with the fluids leaving the flesh. The balance seems to tip differently for cockles and razor clams on the first hand and for mussels, donax and carpet shell clams on the other hand. Thus it confirms the conclusion made by Vidal et al. (2009)[12] based on two bivalve species: the cooking process affects the toxin concentration in bivalves in a way that is species-specific. Although for cockles and clams, Vidal et al. (2009)[12] did not use exactly the same cooking processes, they suggested that the differences found were more likely related to the species than to the differences in treatment.

The decrease in DA concentrations for razor clams could be explained by their difference in DA storage site. Razor clams are a species known to accumulate a significant part of DA in edible tissues whereas the other species accumulate DA almost exclusively in digestive glands. If we suppose that DA left the flesh with fluids in a two-step process: 1) dispersion from the storage site to the entire tissue; and 2) dispersion from the tissue to the fluids; it could be concluded that, in razor clams, part of the DA should have only the second step to undertake, thus it could lead to greater loss of DA with fluids. DA distribution in cockles is not well known thus this explanation cannot be used and verified for this species.

On the contrary, the increase in DA concentrations in cooked mussels, carpet shell clams and donax, means that the weight loss is proportionally greater than the DA loss with the fluids leaving the flesh, which could be explained by a lower accumulation of DA in aqueous tissues.

Moreover, when DA content was analysed in mussels with the cooking juice, there was no significant difference in DA concentration after cooking. Thus the cooking juice decreases the DA concentration in cooked mussels compared with cooked mussels without juice. Because the cooking juice comes from the intervalvar liquid, it can be concluded that the intervalvar liquid is proportionally less concentrated than the mussel flesh, which is consistent with analyses made without cooking juice.

Table 5. Comparison of (raw toxin concentration / cooked toxin concentration) ratio values for OAs and SPX toxins analysed in mussel matrix obtained for two or three different experiments (depending on bivalve species). A ratio greater than one means a decrease in DA concentration in whole flesh due to the cooking process whereas a ratio of less than one means an increase

\begin{tabular}{ccccc}
\hline Toxin in bivalve & \multicolumn{4}{c}{ (Raw concentration / Cooked concentration) ratio } \\
\cline { 2 - 5 } species & Exp 1 & Exp 2 & Exp 3 & Mean \\
\hline OA in Mussel * & 1.74 & 1.79 & 1.34 & 1.62 \\
OA in Mussel & 0.39 & 0.78 & nd & 0.58 \\
SPX in Mussel & 0.69 & 0.81 & nd & 0.75 \\
\hline
\end{tabular}

* : with cooking juice; without cooking juice; nd : not determined

\subsubsection{Cooking Process Impact on Lipophilic Toxin Concentrations}

Concerning OAs and SPX, two toxin families included in the lipophilic toxin group, experiments were performed on raw and cooked mussels (with or without the cooking juice) (Table 5). For each toxin, an increase in toxin concentration is observed for mussels cooked and analysed without cooking juice. The cooking process leads to fluid loss, but because of their lipophilic nature, the toxins do not leave the 
tissue with fluid, resulting in a toxin concentration in flesh. As observed in other studies, there is an overall increase as a result of the cooking process. Despite the differences in increase rates between other studies and ours, the results are consistent[13,15-16]. The conclusion is therefore also that OAs and SPX remain concentrated in the hepatopancreas after cooking.

When cooked mussels were analysed with cooking juice (derived from intervalvar liquid), the toxin concentrations decreased in comparison with mussels analysed without intervalvar liquid (for cooked or raw mussels). This means that the intervalvar liquid leads to a dilution of lipophilic toxins. Thus, it can be concluded that the lipophilic toxin concentration in intervalvar liquid is proportionally lower than that of the mussel flesh. In view of the lipophilic nature of these toxins, cooking effects on toxin concentrations should not be species-specific, as is the case for DA, however further experimentation should be conducted to confirm this hypothesis.

\subsubsection{Consequences of Cooking Process Impact on Phycotoxin Concentrations}

Experiments on the cooking process on different bivalve species and different kinds of phycotoxins revealed that phycotoxin concentrations in bivalves were affected by cooking in different ways according to i) the kind of toxin, ii) the shellfish species and iii) the presence or absence of cooking juice.

The current banning levels are based on raw bivalves. Thus, as mentioned by Vidal et al. (2009)[12], it seems clear that these banning levels may over- or under-protect consumers when shellfish are cooked. In this way, a reflection has been undertaken by McCarron et al. (2008)[15] with regard to sample pretreatment for the analysis of lipophilic toxins in mussels to improve the methodology applied in regulatory monitoring designed to ensure consumer safety. Indeed, the results presented in this study confirm that for lipophilic toxins, analysis of cooked mussels (reflecting most closely what is eaten) (without cooking juice) leads to an increase in toxin concentrations. This increase may push the toxin level over the regulatory limit. Thus, McCarron et al. (2008)[15] mentioned that, from an analytical perspective, the use of a cooking or heating phase as a pretreatment prior to analysis has a number of advantages. However, if a cooking phase was implemented, the impact on the regulatory decision-making process would have to be carefully considered because it could lead to prolonged closure of shellfish production areas.

For DA, the problem is also more complicated, as cooking (allowing water loss) resulted in an increase or a decrease in the concentration of the toxin depending on the bivalve species. Thus if a cooking phase was implemented, it should depend on the bivalve species (otherwise it may be more or less protective for consumer health). This is why Vidal et al. (2009)[12] estimated that, while the approach might be correct, in the sense that it could come closer to the actual levels that consumers ingest, the direct introduction of these pre-processing stages without adapting banning levels, (that are in general defined for raw shellfish) could produce differences in the actual banning levels used in the different monitoring systems or when dealing with different species.

\section{Conclusions}

In view of the information presented in this paper, two forms of inter-species variability have been observed: inter-species variability of contamination and inter-species variability in terms of cooking impact (for DA at least). Concerning the inter-species variability of contamination, cockles appear to be the most contaminated species for DA and SPX, whereas mussels and cockles are the most highly contaminated species for OAs. Concerning the cooking impact on phycotoxin levels, the cooking process leads to an increase in DA concentrations in cooked bivalves for donax, mussels and carpet shell clams, whereas it leads to a decrease in DA concentration for cockles and razor clams. For lipophilic toxins (OAs and SPX), the cooking process causes an increase in toxin concentrations in cooked mussels.

These variabilities must be taken into consideration in exposure assessments and in the design of regulatory monitoring programs. For monitoring purposes, the use of the appropriate species for toxin quantification is crucial. Moreover, the choice between the conservation of the current regulatory monitoring design based on the analysis of raw bivalves and the implementation of a toxin quantification of cooked bivalves should be carefully assessed. This should notably be based on the mode of bivalve consumption, the impact of the cooking process, consequences for human health and aquaculture closures. For DA, this reflection should be made for each bivalve species due to the fact that the cooking process affects the DA concentrations in a bivalve species-specific manner.

\section{Funding Sources}

This work was supported by a grant from the Baseline project: "Selection and improving of fit-for-purpose sampling procedures for specific foods and risks", part of the European Seventh Framework Programme. Grant Agreement number: 222738.

\section{ACKNOWLEDGMENTS}

The authors offer special thanks to Sally Ferguson for reviewing the English translation.

\section{REFERENCES}


[1] Shumway SE, Van Egmond HP, Hurst JW, Bean LL. 1995. Management of shellfish resources. In: Hallegraeff, G.M., Anderson, D.M., and Cembella, A.D., (ed.), Manual on harmful marine microalgae. Paris (France): IOC manuals and guides no. 33. Intergovernmental Oceanographic Commission of UNESCO, Paris, France; p. 433-474.

[2] Van Dolah FM. 2000. Marine algal toxins: origins, health effects, and their increased occurrence. Environ. Health Perspect. 108:S133-141.

[3] Wright JLC, Boyd RK, De Freitas ASW, Falk M, Foxall RA, Jamieson WD, et al. 1989. Identification of domoic acid, a neuroexcitatory amino acid, in toxic mussels from eastern P.E.I. Can. J. Chem. 67:481-490.

[4] Aune T, Yndestad M. 1993. Diarrhetic shellfish poisoning. In: I.R. Falconer Academic Press (ed.), San Diego: Algal Toxins in Seafood and Drinking Water; p. 87-104.

[5] EFSA (European Food Safety Authority). 2010. Scientific Opinion on marine biotoxins in shellfish - Cyclic imines (spirolides, gymnodimines, pinnatoxins and pteriatoxins). The EFSA Journal. 1628:1-39.

[6] Hess P, Gallacher S, Bates LA, Brown N, Quilliam MA. 2001. Determination and confirmation of the amnesic shellfish poisoning toxin, domoic acid, in shellfish from Scotland by liquid chromatography and mass spectrometry. J. AOAC Int 84:1657-1667.

[7] James KJ, Gillman M, Amandi MF, Lopez-Rivera A, Puente PF, Lehane M, et al. 2005. Amnesic shellfish poisoning in bivalve molluscs in Ireland. Toxicon. 46:852-858.

[8] Frémy JM, Lassus P. 2001. Toxines d'algues dans l'alimentation. In: Ifremer (ed.), Plouzané, (France), pp 558.

[9] Reizopolou S, Strogyloudi E, Giannakourou A, Pagou K, Hatzianestis I, Pyrgaki C, Graneli E. 2008. Okadaic acid accumulation in macrofilter feeders subjected to natural blooms of Dinophysis acuminata. Harmful Algae. 7:228-234.

[10] Hatfield CL, Gauglitz EJ, Barnett HJ, Lund JAK, Wekell JC, Eklund M. 1995. The fate of domoic acid in dungeness Crab (Cancer magister) as a function of processing. J. Shellfish Res. 14:359-363.

[11] McCarron P, Hess P. 2006. Tissue distribution and effects of heat treatments on the content of domoic acid in blue mussels, Mytilus edulis. Toxicon. 47:473-479.

[12] Vidal A, Correa J, Blanco J. 2009. Effect of some habitual cooking processes on the domoic acid concentration in the cockle (Cerastoderma edule) and Manila clam (Ruditapes philippinarum). Food Addit. Contam. Part A Chem. Anal. Control. Expo. Risk Assess. 26:1089-1095.

[13] Hess P, Nguyen L, Aasen J, Keogh M, Kilcoyne J, McCarron P, Aune T. 2005. Tissue distribution, effects of cooking and parameters affecting the extraction of azaspiracids from mussels, Mytilus edulis, prior to analysis by liquid chromatography coupled to mass spectrometry. Toxicon. 46:62-71.

[14] McCarron P., Kilcoyne J., Miles C.O., Hess P. 2009. Formation of Azaspiracids -3, -4, -6, and -9 via decarboxylation of darboxyazaspiracid metabolites from shellfish. J. Agric. Food Chem. 57: 160-169

[15] McCarron P, Kilcoyne J, Hess P. 2008. Effects of cooking and heat treatment on concentration and tissue distribution of okadaic acid and dinophysistoxin-2 in mussels (Mytilus edulis). Toxicon. 51:1081-1089.

[16] Reboreda A, Lago J, Chapela MJ, Vieites JM, Botana LM, Alfonso A, Cabado AG. 2010. Decrease of marine toxin content in bivalves by industrial processes. Toxicon. 55:235-243.

[17] EFSA (European Food Safety Agency). 2009. Statement of the Panel on Contaminants in the Food Chain on a request from the European Commission on the Influence of processing on the levels of lipophilic marine biotoxins in bivalve molluscs. The EFSA Journal. 1016:1-10.

[18] Quilliam MA, Xie M, Carpetstaff WR. 1995. Rapid extraction and cleanup for liquid chromatographic determination of domoic acid in unsalted seafood. J. AOAC Int. 78:543-554.

[19] Gerssen, A., McElhinney, M.A., Mulder, P.P.J., Bire, R., Hess, P., De Boer, J. 2009. Solid phase extraction for removal of matrix effects in lipophilic marine toxin analysis by liquid chromatography-tandem mass spectrometry. Analytical and Bioanalytical Chemistry, 394, 1213-1226.

[20] Vale P, Sampayo MAM. 2001. Domoic acid in Portuguese shellfish and fish. Toxicon. 39:893 - 904.

[21] Grigoriadou KI, Mouratidou T, Katikou P. 2005. Investigation on the presence of domoic acid in Greek shellfish. Harmful Algae. 4:717-723.

[22] Mafra Jr LL, Bricelj VM, Ouellette C, Léger C, Bates SS. 2009. Mechanisms contributing to low domoic acid uptake by oysters feeding on Pseudo-nitzschia cells. I. Filtration and pseudofeces production. Aquat. Biol. 6:201-212.

[23] Mc Carron P. and Hess P., 2006. Tissue distribution and effects of heat treatments on the content of domoic acid in blue mussels, Mytilus edulis. Toxicon 47 : 473-479. 